\title{
Repercussões da Exploração Petrolífera sobre as transformações urbanas de Macaé (RJ)
}

\author{
Thereza Carvalho ${ }^{1}$ \\ Wandilson Guimarães ${ }^{2}$ \\ Jonas Delecave ${ }^{3}$
}

\begin{abstract}
Resumo
Este artigo apresenta resultados preliminares de uma pesquisa interdisciplinar financiada, em parte, com recursos do Edital CNPq n $003 / 2008$, concedidos ao LACTA/UFF, e parte com recursos do Edital PIBIC/UFF de 2009/2010. Examina aspectos das repercussões territoriais que a geração da riqueza concentrada e cumulativa gera sobre a morfologia e as funcionalidades urbanas do sitio onde a sua produção está localizada, neste caso sobre a cidade de Macaé. Serão aqui destacadas algumas transformações urbanas associadas àquela produção. A gênese de segmentos urbanos produtivos monofuncionais vem se multiplicando a partir da instalação da Petrobrás assim como, também, significativas mudanças tem sido introduzidas nas tipologias das edificações de função residencial. Verifica-se, ao mesmo tempo, a fragmentação do tecido urbano consolidado decorrente da sobrecarga e congestionamento das redes de provisão de serviços de saneamento e transporte. Foram realizadas pesquisas documentais, cartográficas e visitas de campo, além de entrevistas com moradores em Macaé. A análise dos resultados permitiu a percepção de novas relações entre morfologia e processos sócio-econômicos em construção no município de Macaé.
\end{abstract}

Palavras-chave: morfologia urbana; Macaé; extração petrolífera; transformações urbanas.

\footnotetext{
${ }^{1}$ Professora Associada, PRPPGAU/UFF.

${ }^{2}$ Mestrando, PPGAU/UFF

${ }^{3}$ Bolsista CNPQ/PIBIC, EAU/UFF
}

Abstract

This paper presents preliminary results of an interdisciplinary research financed, in part, with resources from the CNPq Edict $n^{\circ} 003 / 2008$, granted to LACTA/UFF, and partly by resources from the 2009/2010 PIBIC/UFF Edict. It examines aspects the territorial repercussions that the generation of concentrated and cumulative richness generates on the urban morphology and functionality of the site where the production is located, in this case the city of Macaé 
(Rio de Janeiro, Brazil). Some of the urban transformations associated to that production will be highlighted. The genesis of monofuntional productive urban segments is being multiplied since Petrobrás was installed there, and so have significant changes been introduced in the residential building typology. Fragmentation of the consolidated urban tissue, due to the overload and congestion of sanitation services and transport networks, are concomitantly verified. Documental and cartographic researches as well as site visits and interviews with people living in Macaé were completed. The analysis of results allowed the perception of new relations between morphology and socio-economic processes being constructed in Macaé.

Key words: urban morphology, Macaé, oil extraction, urban transformations

\section{Introdução}

Este artigo trata da produção do território a partir do exame das formas urbanas e das alterações introduzidas por diferentes Agentes/Atores/Produtores atuantes em Macaé desde a instalação da Petrobrás, na área dos galpões da Leopoldina Railway, junto à Praia de Imbetiba. Examina alguns aspectos das repercussões territoriais que a geração da riqueza concentrada e cumulativa gera sobre a morfologia e as funcionalidades urbanas do sítio onde a sua produção está localizada, ou seja, sobre a cidade de Macaé. Serão aqui analisadas algumas transformações urbanas associadas àquela produção.

A gênese de segmentos urbanos monofuncionais a partir da Petrobrás, atendendo a propósitos produtivos específicos do setor, mostrou-se associada a mudanças morfológicas significativas com alteração de traçados de ruas, assim como também, com a geração de novos ou intensificação dos fluxos anteriores de carros e transportes de carga. Segmentos urbanos monofuncionais estão sendo igualmente produzidos por outros "atores" municipais públicos e privados, na expectativa de atendimento à demanda gerada pela Petrobrás. Por outro lado, verifica-se a fragmentação do tecido urbano consolidado, decorrente da sobrecarga e congestionamento das redes de provisão de serviços de saneamento e transporte. A sobredemanda por moradias para outros grupos populacionais, cuja renda percebida não é atendida pelo "novo mercado" imobiliário, tem repercussão direta sobre os valores atribuídos às tipologias existentes, assim como, sobre a capacidade de carga das redes de infraestrutura instaladas e as condições de habitabilidade, bastante diferenciadas por faixa de consumo. As tipologias arquitetônicas e urbanísticas dos "novos" assentamentos, com moradias autoproduzidas, igualmente, para o atendimento da referida sobredemanda habitacional, tem mais uma vez, reforçado a referida fragmentação.

\section{Percepções e perspectivas: modelos de referência e transformações urbanas}

Vários analistas já comentaram sobre a imagem percebida das cidades chamadas mundiais, como repercutem de maneira generalizada sobre outras múltiplas cidades e localidades, enquanto modelo de 
referência e, portanto, parâmetro de configuração/ reprodução de novos territórios. A quantidade de recursos financeiros necessários para manter essa 'vitrine acesa' - a renaissance das referidas cidades mundiais e, também, para manter os excluídos excluídos em locais específicos, é, sem dúvida, constituindo por si só, sinal da afluência e do prestígio e a isca com que querem atrair a morada dos decisores. As consequiências desse modelo vitrine em cada cidade aspirante a algum escalão na hierarquia de centralidades que as tornem visíveis naquela rede de prestígio é, pelas mesmas razões, avassaladora, tanto em termos ambientais e financeiros, quanto sociais, econômicos e morfológicos. Custos enormes são socializados por força dessas circunstâncias.

O conceito de centralidade que o contexto de globalização parece consagrar (Hall, 2008), baseado na competitividade setorial, revela, ao mesmo tempo, uma visão oportunista de um território pontual imaginário, sem relações de contiguidade, e a indiferença ideológica diante de uma materialidade complexa, mas irrelevante para os fins estratégicos dos decisores. Apresenta-se, por conseguinte, indissociavelmente ligado à percepção, da mesma forma irreal da possibilidade de concentração ilimitada de riquezas e benesses e, por razão de consequiência, da socialização ilimitada dos custos sociais, ambientais, econômicos, culturais e institucionais. É sustentável essa prática?

A crise financeira que ora se desenrola parece indicar o contrário. A escala mundial de planejamento, produção e controle de bens e serviços, e, da globalização tem o pressuposto subjacente da existência de um mercado consumidor, cuja expansão, tem escala e distribuição territorial compatíveis com aquela oferta - fato que aparentemente não está a se comprovar (Burgel, 2008). A existência desse mercado nas proporções adequadas exigiria, talvez, outro modelo de crescimento baseado na redistribuição territorial dos vários recursos que o modelo concentrador drena. Os postulados tradicionais - 'há que concentrar para crescer' e 'sem crescimento não pode haver (re)distribuição' - precisariam ser revistos à luz da sua contraparte 'sem redistribuição não há crescimento sustentável, econômica e financeiramente, da riqueza', pois não haverá mais consumidores a altura.

A exclusão por inadequação ou obsolescência de trechos de territórios qualificados e de crescentes grupos de populações, somada à atração que a manifestação da riqueza exerce sobre as populações pobres e miseráveis, condensam-se nas entranhas das cidades mundiais e, também, naquelas não tão mundiais assim, na expectativa de que a teoria dos polos - modelo espacial não comprovado, que defendia a concentração de investimentos e de resultados para a posterior 'percolação' do crescimento econômico para o resto do território e das suas populações - aconteça.

A 'fermentação social' que a friç̧ão entre ricos, pobres e miseráveis gera, particularmente agravada pelo enxugamento do Estado, incluindo das suas obrigações face à totalidade da sociedade, manifesta-se mais intensamente em alguns contextos. A guerra civil mal disfarçada, em disputas entre grupos rivais - ora polícia, ora milícias, ora ladrão e ora traficantes - é uma das manifestações da 
mencionada fricção, que algumas das maiores cidades brasileiras produz com muitos mortos e feridos como resultado e como saldo a pagar, se nada mudar.

A proliferação dos condomínios privados, na gênese de novos segmentos de território, multiplica as fragmentações. Às frentes de urbanização, por autoprovisão, subinfraestruturadas somam-se agora novas urbanizações, destinadas a segmentos de alto padrão de consumo, reforçadas por algum investimento público ou privado, com a instalação de equipamento de saúde e/ou educação, galerias comerciais, shoppings, condomínios residenciais, etc.. Essas novas urbanizações tendem a estar desvinculadas dos centros consolidados da cidade e das suas relações de complementaridade, freqüentemente acessíveis apenas por redes viárias 'exclusivas', ou seja, que não são servidas pela rede de transportes públicos.

\section{Macaé}

Macaé (RJ) ocupa uma área de 1.215,904 km²; segundo estimativa do IBGE teria 206.748 moradores; o TRE contabilizou 84.054 eleitores nas últimas eleições. Desde 1974, quando a Petrobras escolheu a cidade para sediar sua sede da Bacia de Campos, mais de quatro mil empresas se instalaram no município e a população foi multiplicada por três. O petróleo é a maior força econômica de Macaé. Nos próximos dois anos, a meta da Petrobras é produzir 2 milhões e 200 mil barris de óleo por dia. Até 2010, a Petrobras vai investir US\$25,7 bilhões, o equivalente a $80 \%$ dos recursos da empresa em Exploração e Produção para todo o país. Consequentemente, o município tem a maior taxa de criação de novos postos de trabalho do interior do estado, de acordo com pesquisa feita pela Federação das Indústrias do Rio de Janeiro: $13,2 \%$ ao ano ${ }^{\mathrm{i}}$.

A instalação da Petrobras constituiu-se no marco de mudança da dinâmica urbana da cidade, determinando demandas crescentes por moradia, redes de ligações, espaços públicos de convivência, serviços e equipamentos coletivos, todas associadas à expansão da empresa na região. Em 2003, Macaé possuía 7400 empregados diretos da Petrobras, 28.000 funcionários das prestadoras de serviços e aproximadamente 3500 empresas ligadas ao setor petrolífero.

A evolução da cidade de Macaé em termos habitacionais, especialmente após a instalação da Petrobras na década de 70, é expressa pela dualidade entre a cidade formal e informal (BARUQUI, 2004). Condições históricas de posse e propriedade da terra e condicionantes sociais, aliadas às restrições do mercado formal de habitação, com foco nas classes sociais mais altas, somadas ao crescimento populacional verificado nos últimos anos, na expectativa de lucro com as riquezas geradas pela exploração petrolífera, foram alguns dos fatores que contribuíram para o crescimento da cidade informal em Macaé.

A falta de lotes destinados à habitação popular, a quase inexistência ou ineficiência das 
políticas públicas no setor habitacional, geram consequiências como agressão ambiental, invasão e ocupação de áreas ambientalmente frágeis e estratégicas.

Dados construídos por BARUQUI (2004), com base no Atlas de Desenvolvimento Humano no Brasil (PNUD), sobre a cidade formal e informal em Macaé, na década de 90, informa que no períodos de 1991 a 2001, a população cresceu 40,86\%, passando de 94.034 habitantes para 132.461 habitantes, enquanto a taxa de crescimento da população residente em assentamentos informais cresceu 91,96\%, variando de 11.275 habitantes para 21.644 habitantes, resultando em uma taxa de crescimento de $148,96 \%$ para os domicílios informais. Percentual bem superior aos $47,75 \%$ referentes aos domicílios formais em Macaé.

A bibliografia examinada apresenta distintas visões sobre o desenvolvimento da cidade pósimplantação da Petrobras e sobre os impactos territoriais associados às dinâmicas sócio-econômicoambientais resultantes. Alguns autores apontam a melhoria dos índices e indicadores sociais no período compreendido entre a instalação da Petrobras, em 1977, e a atualidade, como suficientes para configurar uma análise positiva de desenvolvimento. Outros autores (NETO, et al, 2006; NADER, 2009) retomam a formulação de desenvolvimento teorizada por Sachs (2004), e avaliam a inserção da Petrobras de forma mais crítica, procurando identificar de que maneira a produção de riqueza foi distribuída, direta ou indiretamente. A participação pública nos processos políticos/administrativos e a

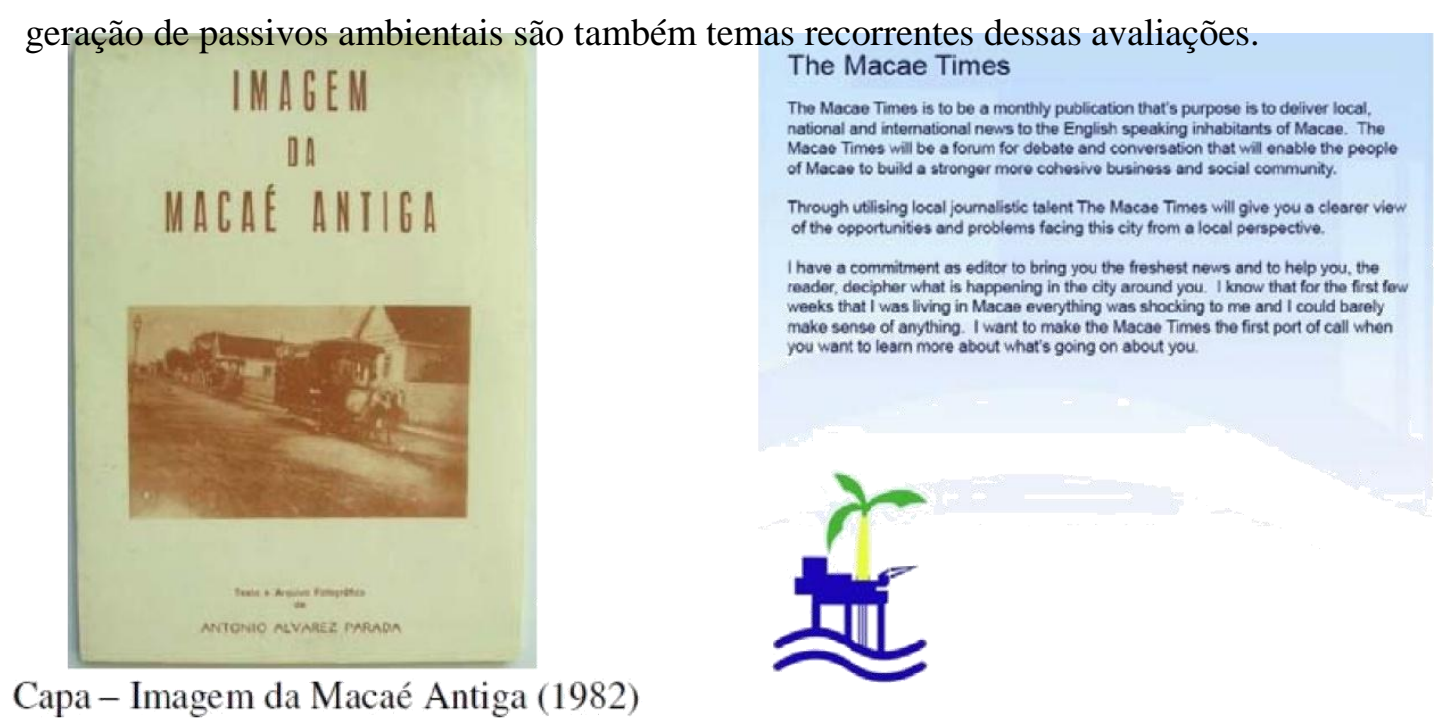

Uma contribuição interessante é a de Vargas (1997), quando trabalha sobre a dimensão simbólica da inserção da Petrobras em Macaé, utilizando-se dos conceitos de Memória e Identidade. Sua análise aponta o despreparo do município ao receber a grande estatal como um dos fatores responsáveis pela geração de conflitos de várias naturezas com repercussões diretas sobre conteúdos 
simbólicos, anteriormente associados a certos locais na cidade. Os diversos relatos analisados parecem convergir para uma "nova" Macaé como uma "plataforma onshore" da Bacia de Campos, com a qual os estrangeiros não estabelecem vínculos afetivos, apenas exploram suas riquezas. Também é percebida como uma mártir do desenvolvimento nacional, pois Macaé estaria sacrificando sua própria identidade por um bem maior. Nesse sentido, o historiador Macaense Antônio Alvarez Parada relata, de forma crítica, as transformações na cidade, após a inserção da Petrobras. Ao mesmo tempo, a 'nova imprensa alternativa' de Macaé, o "The Macaé Times", certamente sinaliza um olhar positivo sobre a visibilidade ampliada que a atividade de extração petrolífera possibilitou à cidade.

\section{Estudo de caso: procedimentos}

A pesquisa, desenvolvida durante o período de 2009/2010, buscou compreender como a instalação da Petrobras, ao mesmo tempo em que se apoiou na e se apropriou da estrutura física da cidade - gerando transformações nas tipologias arquitetônicas e urbanísticas, na rede viária e na distribuição espacial de pólos geradores de fluxos - produziu uma nova dinâmica econômica, social e ambiental. Para isso, foram analisados alguns aspectos das transformações urbanas, associados à geração da riqueza concentrada e cumulativa que a exploração petrolífera parece promover - neste caso sobre a cidade de Macaé, sua morfologia e suas funcionalidades urbanas.

A primeira etapa de análise foi o levantamento bibliográfico, cartográfico e iconográfico sobre Macaé, com especial atenção à sua morfologia urbana, à implantação da Petrobras no município e nas alterações que se seguiram na sua forma urbana, na acessibilidade e na mobilidade resultantes. Nessa etapa, foram realizadas diversas visitas a bibliotecas, sendo o material utilizado predominantemente advindo de dissertações de mestrado e doutorado dos principais programas de pós-graduação do estado do Rio de Janeiro e de levantamentos sócioeconômicos sobre o município e sua região -a Norte Fluminense- realizados por órgãos específicos.

Após uma busca cartográfica nas bibliotecas do IPPUR-UFRJ, PROURB-UFRJ, na biblioteca Central da UFF e na Biblioteca Nacional, somada à planta cadastral fornecida pela prefeitura, foi possível montar um acervo cartográfico compreendendo o período de 1848 - data do primeiro plano de parcelamento para a cidade- até o presente.

Com o objetivo de compreender as novas lógicas urbanas de Macaé, com a instalação da Petrobras, foram utilizadas duas vertentes analíticas, de modo complementar. A primeira, baseada nos procedimentos analíticos de Gianfranco Caniggia, identifica o eixo ordenador da cidade. Analisa comparativamente as 'pré-existências', que ocorrem no tecido urbano de Macaé, a partir da caracterização das tipologias de ruas, lotes e quarteirões, e, as intervenções mais recentes, 
identificando as permanências de determinados elementos de sua morfologia. Assim, procurou-se na evolução dos mapas da cidade, distinguir os elementos herdados e estruturantes do tecido urbano de marcada perenidade, os elementos novos ou aqueles que foram transformados ao longo dos anos, assim como também, as marcas dos que foram eliminados.

O segundo procedimento de análise, apoiado em Lynch, Cullen e Panerai, trata da percepção e da 'construção de imagens' de referência, a partir de certos elementos urbanos novos ou herdados, associadas à formação de identidade. As duas vertentes analíticas se completam na medida em que realçam as relações espaciais e funcionais, entre as 'pré-existências' (Caniggia) e os elos físicos da imagem urbana - como as vias, limites, bairros, pontos nodais e marcos - com os diferentes segmentos urbanos mono-funcionais produzidos a partir de diferentes propósitos de vários coprodutores da cidade. A convergência daquelas relações sinaliza o reconhecimento (e possível apropriação pelos habitantes) do potencial de atração que algumas transformações cumulativas, que vem ocorrendo em áreas específicas de Macaé, exercem sobre diferentes empreendedores.
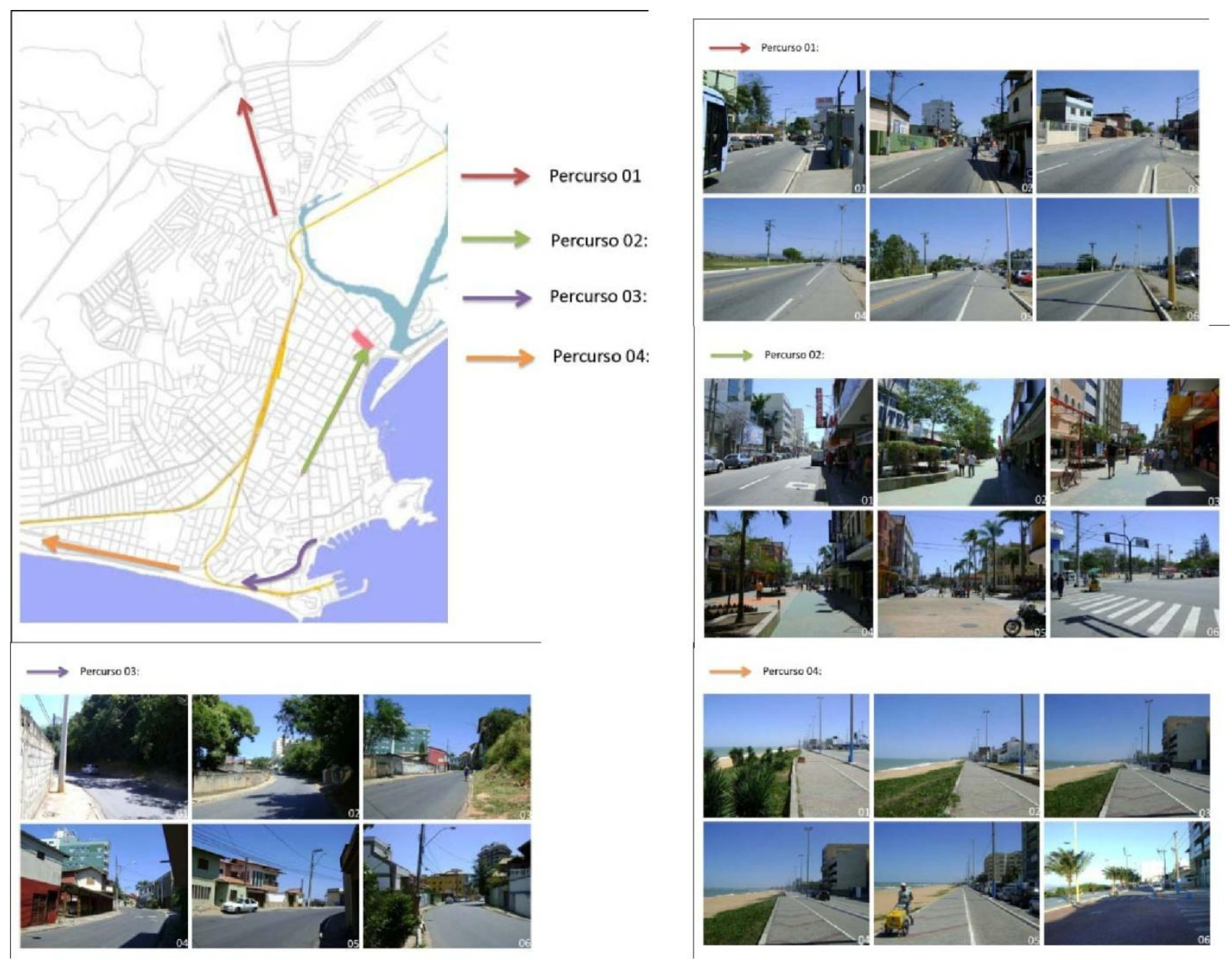
A divergência, por outro lado, aponta para o potencial de refração que certos segmentos urbanos de gênese mono-funcional, recente e custosa, exercem sobre a população e sobre os setores público e privado.

A área escolhida para a sede da Petrobras em Macaé foi o antigo parque de reparos de vagões de trens, pertencente à Leopoldina Railway. O grande terreno, de frente para o mar e no centro histórico da cidade, teve suas oficinas desativadas e seus funcionários realocados para outras regiões, causando grande transtorno às famílias, como relembra Parada em Vargas (1997, pg 64). Da mesma forma que os funcionários da Leopoldina foram realocados, os funcionários da recém-inaugurada Petrobras também o foram, chegando a Macaé de outros municípios, com maiores salários e outras referências de cidade (aqui entendidas como mapas cognitivos).

Naquele momento, surgiram os primeiros conflitos, tanto pela inflação imobiliária decorrente dessa injeção repentina de renda, como pela relação, frequentemente exploratória, que os novos moradores estabeleceram com a cidade, desprezando suas memórias. O exemplo mais marcante dessa relação foi a transformação da praia de Imbetiba - de espaço de fruição, reconhecida como imagem e identidade associada da cidade - em um porto, com interesses econômicos para clientes específicos. O Professor Parada, em suas "Cartas da Província", publicadas semanalmente no jornal Niteroiense "O Fluminense", convida constantemente um amigo fictício a ir "banhar-se na Imbetiba antes que ela acabe". Em entrevistas mais recentes, Zamir Silva afirma que "Imbetiba, por exemplo, que era o cartão de visitas de Macaé, hoje é o cemitério" e Sidney (entrevista realizada em 23 de novembro de 2010) defende que "Imbetiba foi destruída com quebra mares ridículos e vazamentos de óleo constantes". Sobre esse tema, Vargas (1997, pg. 75) aponta que, de forma paradoxal, a destruição da maior referência da cidade se transforma no lugar de memória de uma Macaé que já não existe.

Progressivamente, o espaço de fruição da cidade foi realocado para o Sul. As praias dos bairros Campista e Cavaleiros substituíram Imbetiba, em seu uso recreativo, e construíram os percursos de uma nova Macaé, segmentada por faixa de consumo. Essa região apresenta os mais elevados indicadores sociais e econômicos da cidade, abrigando a elite econômica. Por outro lado são visíveis os propósitos de 'acender a vitrine' e "ficar bonito no filme" do atual planejamento municipal, que promoveu extensa obra de urbanização da orla daqueles bairros sem, contudo, prover a necessária rede de esgotamento sanitário.

O trabalho de campo realizado complementou a análise e identificou, na escala do pedestre, os marcos de referência para a percepção da imagem/legibilidade e entendimento da paisagem urbana ao longo dos percursos/eixos estruturantes da cidade. Essa etapa focalizou a confirmação das continuidades e fragmentações do tecido urbano, identificadas na análise cartográfica realizada, nas etapas anteriores da pesquisa. Permitiu, também, a realização de entrevistas com alguns expoentes locais e o registro das suas respectivas percepções do processo de transformação que "tomou conta de Macaé". 
O primeiro percurso procurou estudar o vetor norte de crescimento urbano, a RJ-168, em direção à BR-101 (rodovia longitudinal brasileira com $4550 \mathrm{~km}$ de extensão, uma das mais importantes rodovias do Brasil, parte da rodovia Pan-Americana). Na referida estrada RJ, observa-se uma grande diferença de escala, fruto do espraiamento promovido pela própria prefeitura, que recentemente realocou alguns de seus setores administrativos, como a Secretaria de Obras, para o extremo norte deste percurso. Observa-se, ainda, como o marco de entrada da cidade, localizado na rótula da RJ-168, é claramente desenhado e implantado para percepção em alta velocidade, criando grande monotonia para o pedestre, com sua escala e velocidade específicas. A RJ-168 se consolida como novo eixo ordenador do crescimento urbano, a partir da instalação das edificações que caracterizam a matriz produtiva da Petrobras em Macaé, com suas respectivas rotas de escoamento, reproduzindo a mesma direção Norte, portanto ortogonal em relação ao eixo ordenador pré-existente ( a rua Direita).

O segundo percurso corresponde à Avenida Rui Barbosa, antiga Rua Direita, culminando na antiga prefeitura e na Praça Washington Luiz. Aqui, vale enfatizar que a rua mais importante do século XIX permanece, hoje ainda, como a mais importante centralidade linear comercial e de fruição urbana da cidade. É interessante notar, ainda, conforme Cullen, a surpresa que a antiga prefeitura causa no transeunte, já que, por estar recuada em relação ao alinhamento da rua, só se permite ser vista à curta distância.

O terceiro percurso corresponde à articulação, em topografia acidentada, de Imbetida com a praia do Campista. Neste percurso, observa-se a grande influência da nova demanda por moradias permanentes e temporárias que a Petrobras gera. São casas e hotéis de alto padrão construtivo, aliados a precárias condições de calçamento, desgastado pelo uso e pela falta de adequada manutenção, plasmando no mesmo território a riqueza recente e a fragilidade do desenvolvimento de Macaé.

Por último, o quarto percurso corresponde à Praia do Campista/Praia do Cavaleiro, e pretende observar em campo a nova escala edilícia da orla da Cidade. Se Imbetiba é uma área consolidada desde o século XIX, com grande significado simbólico para os moradores pré-Petrobras de Macaé (Vargas, 1997) essas duas praias já funcionam como ruptura e frente de expansão da classe alta e média alta, nos últimos anos.

\section{Expansão urbana, conectividade e descontinuidades}

Analisando a cidade através da execução de loteamentos nos bairros do subdistrito de Macaé, que concentram mais de $90 \%$ da população, é possível identificar que ao longo da história da cidade, até a década de 70, a expansão da cidade estava contida na região central, próximo à foz do Rio Macaé, com três vetores definidos, ao Norte, além do rio Macaé, ao Sul, seguindo paralelo à linha 
litorânea e à Rua Direita, e o terceiro em direção ao interior.

A instalação de três grandes 'bases' que caracterizam a ocupação da Petrobras no território, desde o fim da década de 70, marcam significativas mudanças nos eixos que estruturam as redes de ligação, assim como na ampliação, localização e tipologia da oferta habitacional, todas associadas à crescente expansão física da "matriz espacial produtiva” configurada pela Petrobras em Macaé.

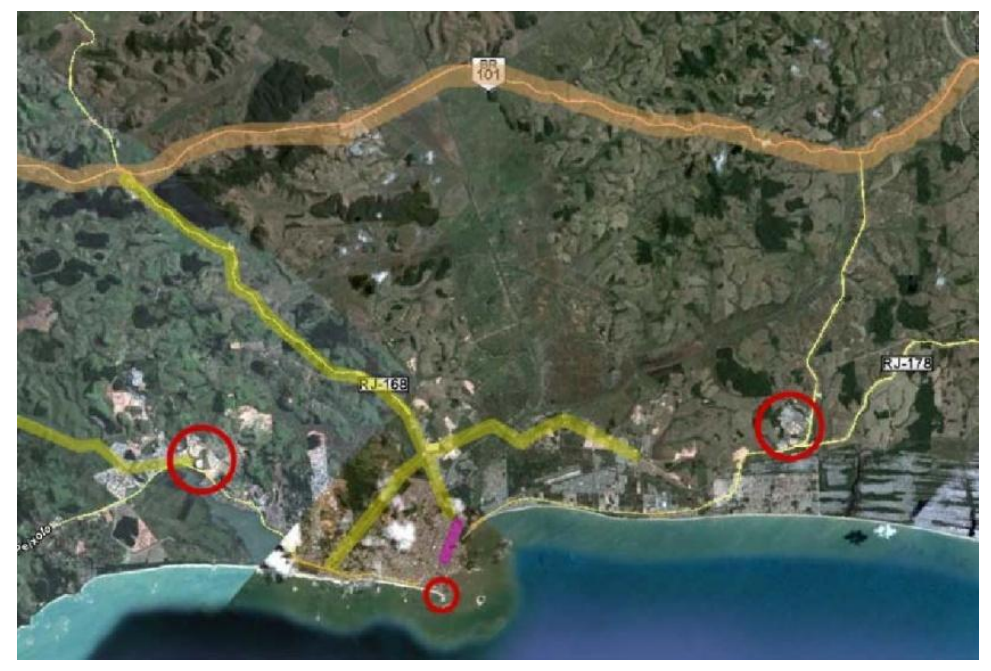

- A base de Imbetiba, localizada na região central, próximo ao antigo porto da cidade e a foz do rio Macaé, é a sede do grupo executivo.

- O Parque dos Tubos de Imboassica, localizado na região Sul, próximo à lagoa de Imboassica e ao atual município de rio das Ostras, às Margens da RJ-106.

- A Estação Cabiúnas, localizada no bairro de Cabiúnas, ao Norte do território de Macaé, às margens da RJ-106, entreposto terrestre de recebimento e distribuição da produção petrolífera offshore.

A consolidação do vetor Norte se dá na última década e é reforçada pelos percursos transversais paralelos, determinados pela matriz espacial da produção do petróleo. Estes passam a ser perpendiculares à linha litorânea, caracterizando uma mudança de $90^{\circ}$ no eixo ordenador anterior da cidade.

A análise dos vetores de expansão da cidade aponta a direção de crescimento linear dos eixos que estruturam as redes de ligação. A RJ-106, construída na década de 40, paralela e, em muitos pontos, tangente à estrada de ferro do fim do século XIX, liga a então capital do estado do Rio de Janeiro, Niterói, à cidade de Campos dos Goytacazes, que cruza Macaé de Norte a Sul pelo litoral, servindo de suporte à expansão dos vetores literâneos. 


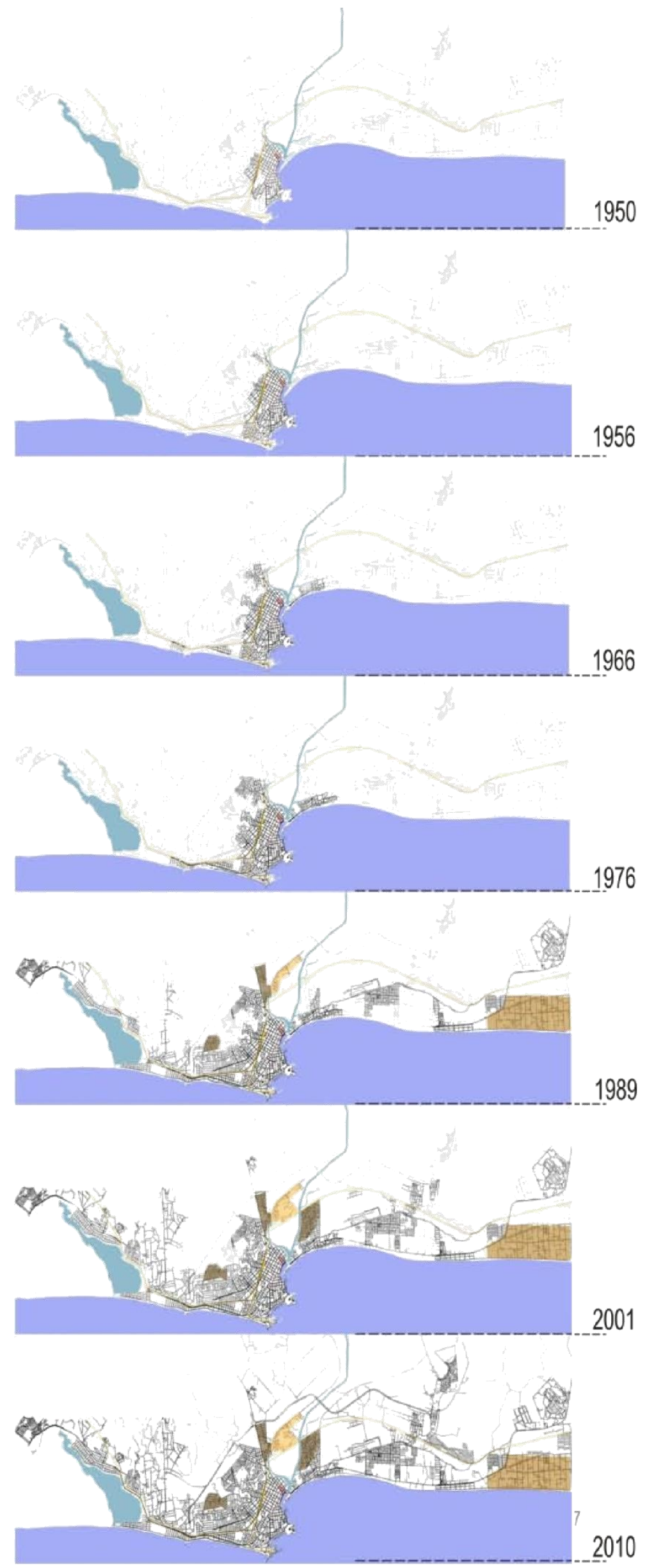

Evolução urbana / áreas de habitação precária
A ligação do centro da cidade à BR101, construída entre as décadas de 50 e 60 , também se constituiu como vetor de expansão, mas desta vez transversal. Por sua vez as vias expressas municipais planejadas e parcialmente construídas, além de ter a função de ser uma alternativa à interligação das extremidades da cidade, consolidam este vetor expansão para o Norte, reforçado pelo Poder Público, como dito no tópico anterior, pela construção de edificações públicas singulares. A expansão alcança o limite territorial do município, junto ao litoral e a Sudoeste, o vizinho Rio das Ostras, sinaliza um possível processo de conurbação com esse município.

Uma importante rede de fluxos construídos na cidade de Macaé pela Petrobras dá suporte terrestre à rede offshore, igualmente transversal à linha da costa. Esta complexa rede é composta por vias aéreas, marítimas, subaquáticas e subterrâneas que têm entre suas funções abastecer as plataformas e navios com suprimentos, equipamentos e mão de obra, além de transportar e distribuir a produção de petróleo e gás. 


\section{Resultados Preliminares}

A perspectiva aqui adotada, de investigar o processo, em andamento, de produção da cidade a partir da morfologia urbana de Macaé, permitiu distinguir propósitos específicos na (re)configuração urbana de Macaé associados a diferentes Agentes/Atores. As intervenções urbanas, praticadas por iniciativa desses que são, na prática, 'coprodutores' da cidade, apresentam algumas características em comum - são monofuncionais, pontuais e setoriais. São, portanto, ao mesmo tempo, indiferentes à diversidade do contexto onde se inserem, às pré-existências, às condicionantes de conectividade e desempenho que a qualidade urbana e ambiental da cidade exige. Alheias às demandas locais externas à sua matriz produtiva, as repercussões morfológicas, espaciais e funcionais das transformações urbanas assim praticadas foram indutoras de um conjunto de diferentes tipologias de rupturas.

Foram consideradas manifestações desse conjunto, a expansão crescente da superfície ocupada, a mudança no eixo ordenador da cidade - de paralelo a ortogonal, à antiga Rua Direita, as mudanças nos padrões funcionais e espaciais de uso e ocupação do solo, as mudanças nos padrões de produção e de consumo de segmentos urbanos monofuncionais, as mudanças nos padrões de formação de novas centralidades e as mudanças nos padrões espaciais das relações multifuncionais entre esses espaços. Foram também consideradas manifestações do referido conjunto de tipologias de rupturas a fragmentação da rede de ligações viárias, decorrente do congestionamento e da sobrecarga crescentes - produzidos pelos Agentes e razões já expostas - e a ampliação dos efeitos desse desgaste sobre o tecido urbano consolidado, associados à visão setorial e pontual mencionada.

O acervo cartográfico constituído para a pesquisa possibilitou a construção dos mapas apresentados, que apontam as relações entre as tipologias identificadas (com base em Caniggia) e os elos físicos (com base em Lynch, Panerai). A referida sequencia de mapas desenvolvida serviu como base para as análises morfológicas e para a identificação dos vetores de expansão urbana.

Sobre essa expansão, pode-se observar o tímido crescimento entre as décadas de $1950 \mathrm{e}$ 1960, com um tecido urbano muito próximo ao previsto, no parcelamento de 1848 . Na década de 1970, porém, após a implantação da Petrobras -1977- observa-se um intenso crescimento, não apenas em população e economia, mas na própria área urbana da cidade de Macaé. Pode-se observar que esse crescimento utilizou a orla e a rodovia como importantes suportes, determinando os vetores principais da cidade. Observa-se ainda que, o 
crescimento se deu por segmentos urbanos monofuncionais, produzidos para o atendimento de propósitos específicos dos quais a articulação com a cidade e a preservação da sua diversidade morfológica, social e ambiental não fazem parte. Os grandes vazios urbanos refletem o enfoque espacialmente pontual e economicamente setorial adotado. Comparando os loteamentos produzidos em meados da década de 1970 até 1989, com os mapas de exclusão social e desenvolvimento urbano de COSTA (2007), que espacializam índices socioeconômicos na cidade, pode-se perceber a crescente territorialização da desigualdade em Macaé. Bairros como Lagomar ou Botafogo, com índices de saneamento e educação baixos, apontam mais uma vez, para um modelo de crescimento econômico segregado e excludente que a morfologia urbana em processo de configuração reflete em Macaé, como em tantas outras cidades brasileiras.

O crescimento da extração do petróleo no estado do Rio de Janeiro (NATAL, 2004), para a qual Macaé contribui com $80 \%$, foi de 222,99\% entre os anos de 1995 e 2001. Verifica-se um aumento do PIB de Macaé de $\mathrm{R} \$ 670.124,30$ para $\mathrm{R} \$ 2.854 .380,00$, entre 1996 e 2002 (CIDE, 2004) e, ao mesmo tempo, um acréscimo do número de domicílios informais de 2833 para 7053, entre 1991 e 2000 (BARUQUI, 2004). Esses domicílios se localizam, majoritariamente, nos bairros: ilhas Malvinas, Nova Holanda, Lagomar, Lixão, Fronteira, Botafogo e Ajuda. Praticamente todos esses assentamentos se localizam em áreas com significativo valor ambiental, onde o status de "preservação" predomina sobre qualquer forma de regulação. No extremo oposto desse "continuum" de segregação social, a população mais rica tem se localizado, principalmente, nas áreas de Campista e Cavaleiros, que substituíram a Praia de Imbetiba, enquanto polos de atração para o lazer e fruição. A avaliação positiva dos índices e indicadores sociais, constatada, parece estar, no contexto analisado, a mascarar a realidade de Macaé 'pela média', ou seja, a melhora se dá em razão do grande acréscimo populacional, com perfil específico melhor qualificado em vários aspectos, que a crescente geração de empregos pela Petrobras promoveu.

A produção da cidade reflete os critérios do seu planejamento. No período de 20012004, os investimentos dos Royalties de Petróleo aplicados na configuração de novos tecidos urbanos revelam a perspectiva da criação de "grandes projetos" sem uma preocupação em reduzir a disparidade socioeconômica da cidade (Dias, 2006, p.122). Ao mesmo tempo, a exploração petrolífera certamente gerou recursos e fluxos que projetou Macaé para uma posição muito superior à que tinha anteriormente, na hierarquia de cidades do estado do Rio de Janeiro. 
Região de Influência de Campos dos Goytacazes - 1966

Niveis de Centralidade/Regiăo de Influência

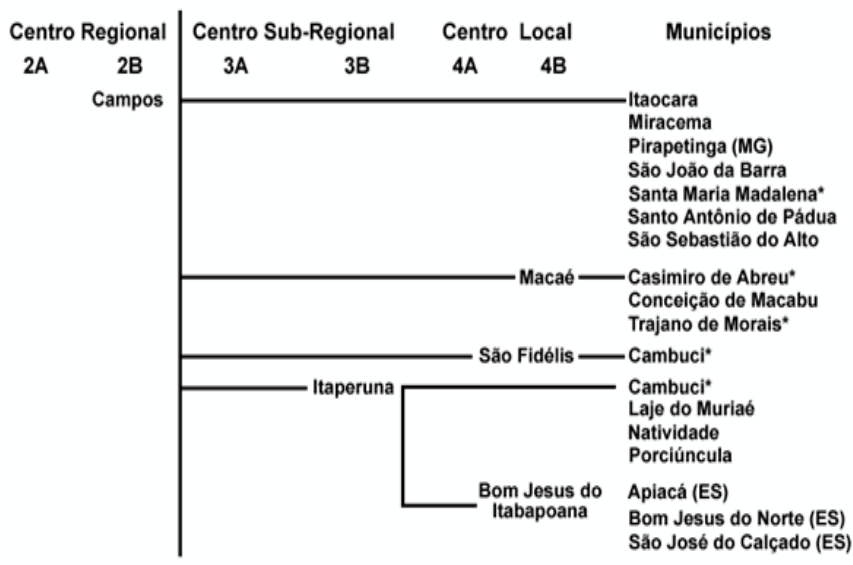

Fonte: IBGE. Divisăo do Brasil em Regiōes Funcionais Urbanas, 1972

Região de Influência de Campos dos Goytacazes e Macaé - 2007

Niveis de Centralidade/Regiăo de Influência

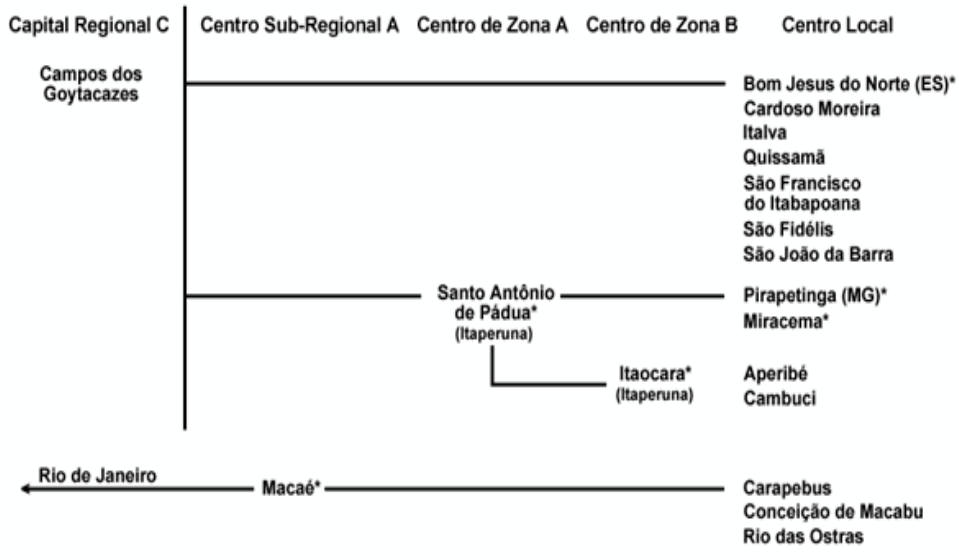

Fonte: IBGE. Regiōes de Influência das Cidades, 2008

Diagrama representado a mudança da posição de Macaé na rede de cidades do Norte Fluminense. Fonte: RIBEIRO, 2009

\section{Considerações finais sobre a produção de segmentos mono-funcionais como critério aparente para a gênese de novos territórios: fragmentação ou outro paradigma de urbanização?}

A finitude das reservas petrolíferas e a obsolescência prevista das edificações e demais estruturas, que caracterizam a sua exploração, é tema e preocupação recorrente das cidades e governos, cuja pujança financeira tem relação direta com a exploração deste recurso. O mesmo acontece em Macaé, onde grande parte das receitas financeiras 
decorrem do recebimento das participações governamentais (Royalties e participações especiais) advindas da exploração Petrolífera. Possibilidade de ausência do recurso mineral é uma das principais justificativas para a defesa do repasse dos recursos. Além do repasse dos recursos financeiros, que por força de disputas federativas pode ser alterado, mesmo antes do início do esgotamento das reservas petrolíferas, ficam as perguntas sobre quais serão as prováveis consequências do declínio produtivo e o que pode ser feito para diminuir os impactos e evitar cenários desfavoráveis.

A escala de intervenções praticadas na exploração da bacia petrolífera mostraram ter repercussões espaciais, funcionais e morfológicas sobre a cidade de Macaé com significativos desdobramentos sobre Rio das Ostras que a continuação da pesquisa está a comprovar. A abrangência territorial das redes de relações funcionais e espaciais que caracterizam essas novas intervenções e seus coprodutores não tem rebatimento na atual estrutura de gestão pública. Novas institucionalidades precisam ser pensadas para a sua avaliação, monitoramento e fiscalização. Novas estratégias de gestão precisam ser pensadas para que se mantenham as condições de planejar o território para o bem comum. Novas abordagens projetuais precisam ser pensadas para que essas intervenções urbanísticas de grande escala preservem e aperfeiçoem os resultados apropriáveis ao bem comum ou, no mínimo, não mais ameacem a coesão territorial que ainda subsiste.

A promoção da equidade social e ambiental depende da consolidação dos vários tecidos urbanos que hoje se apresentam fragmentados, não apenas pela obsolescência e abandono, mas sobretudo pelas gêneses segmentadas decorrentes de intervenções setoriais e pontuais de diversos agentes produtores do território. Dentre os vários desafios que se apresentam ao gestor público, diante dessa realidade, dois se destacam. O primeiro é catalisar essas iniciativas empreendedoras para áreas selecionadas mediante estratégias territoriais que espelhem visões de futuro e consensos, construídos em comum e para o bem comum. O segundo desafio é identificar formas de regulação e gestão dessa tendência, à luz das novas relações do Poder Público com aqueles agentes que preservem os compromissos deste com os propósitos coletivos que o justificam. A parceria com redes acadêmicas de pesquisa e extensão pode contribuir para a consecução deste propósito.

O foco no processo dinâmico da formação de novos segmentos urbanos e no papel da conectividade com eixos pré-existentes na configuração das novas redes de ligação entre pontos de atração no território realça as inter-relações entre os temas de centralidades, da produção dos novos segmentos urbanos (ou urbanização para segmentos de mercado específicos), os espaços públicos de convivência, a acessibilidade e o transporte público. Distintos modelos, espaciais dentre os quais a centralidade linear e o 
policentrismo aparecem em apoio a intervenções, em diferentes pontos no território como polos provedores de serviços e geradores de novas dinâmicas urbanas capazes de promover a qualificação urbano-ambiental de novos trechos ou fragmentos de território. Esses mesmos modelos permitem vislumbrar distintas perspectivas de intervenção, voltadas para a valorização do território qualificado. A promoção da diversidade dos usos do solo pode, potencialmente, contribuir para reduzir percursos e diminuir custos de conexão e de qualificação do solo urbano. Da mesma forma, a densificação controlada colabora para a otimização de custos de produção do conjunto de redes de infraestrutura de transporte, comunicação e provisão de serviços de saneamento.

A potencialização de lugares de referência, focalizando as relações funcionais, espaciais e simbólicas que estabelecem entre si e com a cidade, os padrões espaciais que as caracterizam, aparecem como possível alternativa para o fortalecimento da identidade e apoio ao processo de sedimentação dinâmica das novas intervenções segmentadas com as pré-existências - patrimônios construídos e naturais. O tema da conectividade é condição para a materialização deste objetivo.

O desenvolvimento desta pesquisa aponta para novos temas que abrangerão uma reflexão sobre as "novas práticas" de produção do território, que se destacam pelas escalas física e logística de âmbitos metropolitano, regional e além, e sobre as necessárias estratégias de gestão compatíveis com aquelas escalas.

\section{Referências Bibliográficas:}

BARUQUI, S. S. C. A cidade formal e a cidade informal em Macaé: uma análise do crescimento habitacional na década de 90. 2004. 110 p. Dissertação (Mestrado em Planejamento Regional e Gestão de Cidades), Universidade Candido Mendes, Campos dos Goytacazes, 2004.

BURGEL, Guy. La Revanche des villes. Hachette Littératures, Paris. 2006

CANIGGIA G. Tipologia de la Edificacion Celeste Ediciones, Madrid. 1998

CARVAlHO SANTOS, T. C.; COELHO, C. D. O capital genético das redes de espaços públicos: mutações e persistências. In: GAZZAENO, L. M,; AMORA, A. A.

(Orgs.). Ordem, Desordem, Ordenamento. Urbanismo e Paisagem. Rio de Janeiro:

Ed.UFRJ, 2009.

COSTA, R. C. R. Exclusão social e desenvolvimento humano: um mapeamento das desigualdades e do desenvolvimento sócio-econômico do município de Macaé. Prefeitura de Macaé. 2007. 
CRUZ, J. L. V. Projetos Nacionais, Elites Locais e Regionalismo desenvolvimento e dinâmica territorial no Norte Fluminense. 2003. f.338 Tese (Doutorado em Planejamento Urbano e Regional) - Instituto de Pesquisa e Planejamento Urbano e Regional, Universidade Federal do Rio de Janeiro, Rio de Janeiro. 2003

CULLEN, G. Paisagem urbana. Ed. Martins Fontes, São Paulo. 1983.

DIAS, R. F. L. Urbanização e petróleo: um estudo de caso sobre Macaé no limiar do século XXI. 2006. f.136 Tese (Mestrado em Arquitetura e Urbanismo) - Escola de Arquitetura e Urbanismo, Universidade Federal Fluminense, Niterói. 2006.

HALL, Peter. Conferencia proferida no ciclo de conferencia sobre a cidade do século XXI, realizado no Pavilhão de Portugal, em Lisboa, Portugal. 2008.

LYNCH, K. A boa forma da cidade. Edições 70, Lisboa. 1999.

NASCIMENTO, R. L. P. O impacto da Petrobrás no município de Macaé. Rio de Janeiro, 1999. 109f. Dissertação (Mestrado em Planejamento Urbano e Regional) - Instituto de Pesquisa e Planejamento Urbano e Regional, Universidade Federal do Rio de Janeiro, Rio de Janeiro, 1999.

NATAL, J. Inflexão econômica e dinâmica espacial pós-1996 no Estado do Rio de Janeiro. In: Nova Economia. Belo Horizonte v. 14, n. 3, p. 71-90, set./dez. 2004. NETO, Et Al. influência do petróleo na dinâmica econômica das cidades: um estudo comparativo entre Macaé (Brasil) e Aberdeen (Reino Unido) In: II Jornada Nacional da Produção Científica em Educação Profissional e Tecnológica São Luís/MA - 2007

PANERAI, Ph. Análise Urbana. Editora UnB, Brasília. 2006.

SANTOS, Renato José C., O Declínio da produção de petróleo no Mar do Norte e a estratégia da cidade de Aberdeen. Trabalho de conclusão de curso. MPB, COPPE/UFRJ 2006.

SERRA, Rodrigo V.; MOTHÉ, Natália G.; Sintomas da Maldição dos Recursos Naturais no Município Petrolífero de Campos dos Goytacazes. Artigo Academico. CEFET/CAMPOS 2007.

SILVA, L. C. Urbanização e Segregação Socioespaciais em Macaé/RJ. Tese (Monografia de Graduação) UENF. Campos de Goytacazes.2004.

VARGAS, S. C. B. A cidade plataforma: memória e identidade em Macaé. 1997.

f.185 Tese (Mestrado em História) - Instituto de Ciências Humanas e Filosofia, Universidade Federal Fluminense, Niterói. 1997. 